\title{
Towards Improving the Health Outcome of Hivaids Patients Receiving Antiretroviral Drugs in Low-Income Communities: Will Incorporating Food Supplementation Make a Difference?
}

\section{Timiun GA* \\ Department of Sociology, Benue State University, Nigeria}

*Corresponding author: Godwin Aondohemba Timiun, Department of Sociology, Benue State University, Makurdi, Nigeria, Tel: +2347060980043; Email: gatimiun@gmail.coma

\section{Research Article}

Volume 2 Issue 4

Received Date: July 16, 2019

Published Date: July 29, 2019

DOI: $10.23880 /$ jqhe- 16000132

\section{Abstract}

The benefits of ART in assisting patients recover from debilitating health conditions and assuming their social responsibilities have been reported in Haiti, South Africa and Tanzania. However, lack of food may be a factor influencing the recovery of those on ART from debilitating health conditions. This paper discusses the possible impact of incorporating food supplementation in the care of individuals on ART in low income communities and health outcome in Nigeria. A sample of 1,621 respondents was collected using multi-stage and purposive sampling methods. Structured and in-depth interviews were used for data collection. SPSS (version 21) was used for quantitative data analysis while the qualitative data was analysed thematically. There are $46.3 \%$ maen and 53.7\% women. Generally, their income is low, $70.7 \%$ are earning less than N25, 000 (approximately \$125 USD) per month. It is evident that some low income HIV/AIDS patients receiving treatment in Nigeria, and perhaps in other low income communities lack food. Those who are unable to adequately feed themselves would experience longer period of recuperation from debilitating health conditions; thereby hiking the possibility of stigmatisation and tendency to avoid nearby treatment centres where they (HIV patients) would be sighted collecting drugs, which may sometimes lead to the inability to replenish exhausted stock of drugs, and treatment failure among low income earners. Food supplementation may assist in improving the health outcomes of HIV/AIDS patients if it is incorporated in the overall treatment package. It would also enhance sustainable fight against HIV/AIDS pandemic, given that effective preventive measures are in place against its continuous spread and those already infected are adequately cared for. Incorporating food supplementation in the overall treatment package of HIV/AIDS patients in low income communities who not able to adequately feed themselves would make a difference in their health outcomes. Keywords: HIV/AIDS; Antiretroviral; Health outcome; Low income; Food supplementation.

Keywords: HIV; Data Collection; Physical Exercise; Disease 


\section{Journal of Quality in Health Care \& Economics}

\section{Introduction}

Human Immune Deficiency Syndrome (HIV) is a deadly disease that has killed over39 million people globally, while over 35 million people are living with the disease since the first case was identified in 1981 [1]. Despite the programmes intervention to halt the spread of HIV, 3.6 million individuals are living with the disease in Nigeria [2]. Out of the figure living with HIV in Nigeria, 2, 224, 857 individuals were placed on Anti-retroviral Drug by the year 2013 [3]. The benefits of ART in assisting patients recover from debilitating health conditions and assuming their social responsibilities have been reported in Haiti South Africa and Tanzania [4-6]. However, lack of food may be a factor influencing the recovery of those on ART from debilitating health conditions. This paper discusses the possible impact of incorporating food supplementation in the care of individuals on ART in low income communities and health outcome in Nigeria.

Under normal healthy conditions, the nutritional requirements of individuals may vary based on their physical activities, age, sex, body size and composition, climate and physiological state; while absence of food, unhealthy diet and lack of physical activity are leading global risk to health [7]. The view that lack of food could be impediment to individuals' wellbeing was also expressed by authors who attributed hawking sex among women in Lagos, Ondo, Osun and Ekiti States in Nigeria to lack of food, unemployment and money [8,9]. Unhealthy sexual behaviours such as unprotected sex and outcomes of sexually transmitted diseases, unwanted pregnancies and abortion were observed among these women who traded sex for means of survival, food inclusive [8]. Other studies have also expressed similar opinion on the impact of poverty that could manifest in lack of basic needs including food on risky sexual behaviours and wellbeing [10-12]. Another author, Hunter [13] examined the influence of subsistence and conspicuous consumption on seeking sexual relationships that would yield benefits in form of gifts. The women in rural and urban areas of KwaZulu Natal, South Africa who had multiple sexual partners collected gifts from them in order to pay bills including accommodation, clothing, food and maintenance of cell phones. Despite the glaring evidence suggesting that poverty may manifest in lack of basic needs including food to influence health behaviours, less attention has been given to the impact of lack of food on recuperation of HIV patients on ART in low income areas including Nigeria.

\section{Methods}

Evidence supporting our proportion in this paper has been derived form a sample of 1,621 (864 women; 757 men) respondents which was collected from 2 clinics (Mkar; Aliade) and other 2 locations (Jyovkundan; Udei) using multi-stage and purposive sampling methods. A probability sampling without replacement (raffle draws) was used in selecting Gwer West (urban area) and Guma (rural area) from the homogeneous settlements of Ichongu block; while Gboko (urban area) and Konshisha (rural area) were selected from the Ipusu using the same method. General Hospital, Aliade was then selected from Gwer West, while NKST Hospital, Mkar was selected from Gboko to obtain samples of those living with HIV. The table of random numbers was used in selecting Udei from Guma out of several other rural settlements such as Kaseyor, Yerwata, Ukohor, Umenga, Agasha, Daudu, Uluva, Yogbo etc. Similarly, Jovkyundan was selected from Konshisha out of other rural settlements such as TseAgberagba, Gungul, Korinya, Agbeede, Awajir, Tsuwe, Mbaakpur, Achoho, Iber, Akputu etc.

An eight page questionnaire with closed and open ended questions was used for quantitative data collection amongst 805 HIV seropositive clinic attendees and 796 HIV seronegative individuals on background characteristics, motivations for sexual relationships, serodiscordant relationships, risky sexual behaviours, and treatment received at clinic centers. The target groups were individuals including men and women aged between 18 and 65 years old, who were presumed to be sexually active, in relationship (partners), had tested for HIV prior to the study, and were either HIV positive or negative. The sample excluded those below the age of 18years; those with AIDS and opportunistic infections, pregnant women and those who were mentally ill. .

At the completion of data collection, the responses were coded and entered into Statistical Product and Service Solution (SPSS) version 21 software, which has provision for the Generalised Linear Regression with Cumulative Link, was used for the analysis of quantitative data. However, in this article, percentage distribution of relevant variables has been used to indicate the magnitude of the issues in questions while further insight has been drawn from the qualitative data.

\section{Qualitative Methods}

In this segment of data collection, purposive sampling was used in selecting 20 respondents who participated in indepth interviews. Five individuals were selected in each 


\section{Journal of Quality in Health Care \& Economics}

location. The interviews were conducted in Tiv language using a guide with questions on structural factors, background characteristics, knowledge and attitude towards HIV, risky sexual behaviours poverty, stigma and discrimination. An audio recorder was used for recording the discussions during the in-depth interviews for the purpose of transcription after the data collection sessions. The data were transcribed and analysed by the researcher following the principles of concurrent transformative strategy (either nested or concurrent triangulation). It ensures that better insight would be obtained from the qualitative data to provide deeper understanding of some findings from the quantitative. The findings from qualitative data provided further insight into the intricacies of living with HIV under low income and the desire for incorporating food supplementation as component of care available for those living HIV at the treatment centres.

\section{Results}

Most of the respondents in this study, 1,488 (92.9\%) are between the reproductive ages of 18 and 49 years, while $133(7.1 \%)$ are above the age of 50 years. The young people are more sexually active and more exposed to the risk of HIV/AIDS; thus, they constitute a higher percentage of respondents in the present study. Amongst the respondents, $7.6 \%$ have not obtained formal education, while $11.7 \%$ have completed only primary education. The percentage of completion of secondary education seems to be high (47.5\%) because all respondents who have completed some form of secondary education (the junior secondary school) are in this category. The respondents who have completed some form of higher education (Diploma, Higher Diploma, First degree, Postgraduate) are 530 (33.1\%).

Eight hundred and twenty (51.2\%) of the individuals, slightly more than half of the total respondents are in marital relationships, while the rest, 781 (48.8\%) are single, just with variations in social circumstances of death of a partner (widowed), divorced, separated and not officially married according to the tradition

Majority of the respondents, 1,186 (74.1\%) earn less than twenty five thousand naira (AUD 168.91) a month, while few others, $30(1.9 \%)$ earn more than one hundred thousand naira (AUD 675.67) a month. As shown in Table1, most of the respondents are engaged in low income earning ventures such as subsistence farming and petty businesses. All the respondents in the study who are living with HIV were placed on the ART at the time of the interviews. Some have taken ART for over one but less than 3 years $(291 ; 36.1 \%)$, some for over three but less than 5 years $(206 ; 25.6 \%)$, while $149(18.5 \%)$ have been taking ART for over 5 years at the time of the interview.

Some of the respondents have shown a dislike for HIV. Seven hundred and thirty seven (92.6\%) respondents who were HIV negative said they "will feel bad if infected with HIV" (see Table 4.51), though they have people are close to them living with HIV. The individuals known to the respondents as living with HIV/AIDS are mostly friends $(563 ; 35.2 \%)$, husband or wife $(189 ; 11.8 \%)$, sister $(219 ; 13.7 \%)$ and brother $(176 ; 11.0 \%)$. Others are parents $(38 ; 2.4 \%)$ and children $(27 ; 1.7 \%$; see Table 1$)$.

\begin{tabular}{|c|c|c|}
\hline \multicolumn{2}{|c|}{ Variables } & Frequency \\
\hline \multicolumn{3}{|c|}{ Income } \\
\hline Less than 25,000 & 1186 & 74.1 \\
\hline $25,000-49,000$ & 287 & 17.9 \\
\hline $50,000-90,000$ & 98 & 6.1 \\
\hline $100,000+$ & 30 & 1.9 \\
\hline Total & 1601 & 100 \\
\hline \multicolumn{3}{|c|}{ Need Money } \\
\hline Strongly disagree & 291 & 18.2 \\
\hline Disagree & 671 & 41.9 \\
\hline Agree & 512 & 32 \\
\hline Strongly agree & 127 & 7.9 \\
\hline Total & 1601 & 100 \\
\hline \multicolumn{2}{|c|}{ Period of time Respondents with HIV have collected HIV Drug } \\
\hline Less than one year & 159 & 19.8 \\
\hline One to less than 3years & 291 & 36.1 \\
\hline Three to less than 5years & 206 & 25.6 \\
\hline 5years + & 149 & 185 \\
\hline
\end{tabular}

Timiun GA. Towards Improving the Health Outcome of Hivaids Patients Receiving Antiretroviral Drugs in Low-Income Communities: Will Incorporating Food 


\section{Journal of Quality in Health Care \& Economics}

\begin{tabular}{|c|c|c|}
\hline Total & 1601 & 100 \\
\hline Age & Frequency & Percentage \\
\hline $18-19 y r s$ & 163 & 10.2 \\
\hline $20-24 y r s$ & 293 & 18.3 \\
\hline $25-29 y r s$ & 342 & 21.4 \\
\hline $30-34 y r s$ & 336 & 21 \\
\hline 35-39yrs & 120 & 7.5 \\
\hline 40-44yrs & 136 & 8.5 \\
\hline $45-49 y r s$ & 98 & 6.1 \\
\hline $50-54 y r s$ & 67 & 4.2 \\
\hline $55-59 y r s$ & 35 & 2.2 \\
\hline $60+$ & 110.7 & \\
\hline Total & 1601 & 100 \\
\hline \multicolumn{3}{|c|}{ Relationship Status } \\
\hline Married & 820 & 51.2 \\
\hline Single & 527 & 32.9 \\
\hline Widowed & 123 & 7.7 \\
\hline Divorced & 59 & 3.7 \\
\hline Separated & 65 & 4.1 \\
\hline Cohabiting & 7 & 0.4 \\
\hline Total & 1601 & 100 \\
\hline \multicolumn{3}{|c|}{ Education } \\
\hline No formal schooling & 122 & 7.6 \\
\hline Primary & 188 & 11.7 \\
\hline Secondary & 761 & 47.5 \\
\hline Tertiary & 530 & 33.1 \\
\hline Total & 1601 & 100 \\
\hline \multicolumn{3}{|c|}{ whether they will feel bad if infected with HIV Response } \\
\hline Strongly disagree & 30 & 3.8 \\
\hline Disagree & 29 & 3.6 \\
\hline Agree & 307 & 38.6 \\
\hline Strongly agree & 430 & 54 \\
\hline Total & 796 & 100 \\
\hline \multicolumn{3}{|c|}{ Knowledge of someone living with HIV Knowledge } \\
\hline Yes & 1504 & 93.9 \\
\hline No & 97 & 6.1 \\
\hline Total & 1601 & 100 \\
\hline \multicolumn{3}{|c|}{ Relationship of Respondents with someone living with HIV/AIDS } \\
\hline Husband/Wife & 189 & 11.8 \\
\hline Brother & 176 & 11 \\
\hline Sister & 219 & 13.7 \\
\hline Friend & 563 & 35.2 \\
\hline Parents & 38 & 2.4 \\
\hline Children & 27 & 1.7 \\
\hline Others & 292 & 18.2 \\
\hline Don't know & 97 & 6.1 \\
\hline Total & 1601 & 100 \\
\hline
\end{tabular}

Table 1: Table 1 Socio-economic Characteristics of Respondents and HIV/AIDS Variables.

Derived from Timiun, 2017 [14]. 


\section{Journal of Quality in Health Care \& Economics}

A glimpse at the qualitative data reveals the desire of the people in the communities with regard to treatment of those living with HIV/AIDS. A respondent stated that HIV patient receiving drugs would be better if they are also given food. She said "the government and other individuals should assist in providing food for those infected, the suffering is so much to be borne by the individuals alone" (Male, 35yrs; Married; Secondary; Farmer).

Another respondent expressed a similar view by opining that "food is important, those who are HIV positive should be assisted to get good food" (Female, 38 years; JSS 3 junior secondary school, Widow; Business Tailoring). Furthermore, the issue of food supplementation for HIV/AIDS patients was stressed by another female respondent corroborating the importance of this type of intervention in the treatment of HIV patients. According to her, "they should give those infected food. They should also give them money to do business (Female, 40yrs; Civil servant; married; Primary). To another, "those people with HIV need food, so they should provide them with money and good food. This will help them to be strong and live longer" (Female; Farmer; 60 years; Primary; Widow) Further still, other respondents added their voice by emphasising that "they should help them because it not good to allow them die like that. For me, if I have money, I will buy good food for them" (Female, Farmer; 22years, Primary; Married). Another respondent who also empathised with HIV patients said "If I have money, I will give those infected with HIV, so that they can buy what they need. I will also give them food"(Female, Farmer; 23years; Secondary; single) Wrapping up the evidence supporting the need for introduction of food supplementation in the treatment of HIV/AIDS patients is the submission of one of the patients who stated that "apart from the drugs that the government is giving us, they can also provide food. If you eat good food, you will be healthier, so let them help us with good food" (Male, 45yers; Driver, Secondary; married).

\section{Discussion}

Some of the leading health risk factors are good food and physical exercise among [7]. However, it is only when an individual has energy to move his or her body that physical exercise can be possible, alluding to the importance of food and healthy diet to the wellbeing of almost all people including those who are ill. On the other hand, the capability of a well administered Anti-retroviral treatment in assisting those suffering from HIV/AIDS recuperate is not in doubts [4-6]. The fight against HIV/AIDS pandemic can only be complete when those already infected are properly cared for, and there are also very effective measures in place to prevent the continuous spread of HIV/AIDS. In Nigeria specifically and Sub-Saharan Africa in general, the victory over the spread of HIV/AIDS has been very slow due to poverty and its manifestations $[10,15,16]$. Given these conditions of lack of food among HIV/AIDS patients receiving treatment in low income communities, recuperation period would be longer; thereby hiking the possibility of stigmatisation and tendency to avoid treatment centres where they (HIV patients) would be sighted collecting drugs; they travel longer distances to other drug centres outside their immediate communities, incurring additional burden of high transportation cost leading to inability to replenish exhausted stock of drugs and treatment failure among low income earners [17]. To improve the health outcome of low income HIV patients who are receiving treatment but unable to adequately feed themselves, I suggest that food supplementation should be incorporated into the treatment package. It will positively impact on the psychological and physical wellbeing of the patients as expressed by some of them in the study.

\section{Conclusion}

The ability of Anti-retroviral therapy to assist HIV/AIDS patients recover from debilitating health conditions cannot be contested. However, lack of adequate food constitutes health risk among those receiving treatment. It is evident that low income HIV/AIDS patients receiving treatment in Nigeria, and perhaps in other low income communities lack food. Those who are unable to adequately feed themselves would experience longer period of recuperation from debilitating health conditions; thereby hiking the possibility of stigmatisation and tendency to avoid treatment centres where they (HIV patients) would be sighted collecting drugs, which may lead to inability to replenish exhausted stock of drugs and treatment failure among low income earners. Food supplementation may assist in improving the health outcomes of HIV/AIDS patients if it is incorporated in the overall treatment package. It would also enhance sustainable fight against HIV/AIDS pandemic, given that effective prevention measures are in place against its continuous spread and those who are already infected are adequately cared for. Incorporating food supplementation in the overall treatment package of HIV/AIDS patients in low income communities who are not able to adequately feed 


\section{Journal of Quality in Health Care \& Economics}

themselves would make a difference in their health outcomes.

\section{References}

1. (WHO) World Health Organisation (2014a) Media Centre. HIV/AIDS.

2. (2013) UNAIDS Joint United Nations Program on HIV/AIDS.

3. (2014) National Agency for the Control of AIDS (NACA). Federal Republic of Nigeria, Global AIDS response: country progress report (Nigeria GARPR), Abuja, Nigeria.

4. Robins S (2006) From rights to ritual: AIDS activism and treatment testimonies in South Africa. American Anthropologist 108(2): 312-323.

5. Campbell C, Skovdal M, Madanhire C, Mugurungi O (2011) We, the AIDS people..how antiretroviral therapy enables Zimbabweans living with AIDS to cope with stigma. Am J Public Health 101(6): 10041010.

6. Roura M, Wringe A, Busza J, Nhandi B (2009) 'Just like a fever': a qualitative study on the impact of antiretroviral provision on the normalisation of HIV in rural Tanzania and its implications for prevention. BMC International Health and Human Rights 9: 22.

7. (2018) World Health Organisation (WHO).

8. Oyefara JL (2007) Food insecurity, HIV/AIDS pandemic and sexual behaviour of female commercial sex workers in Lagos metropolis, Nigeria. SAHARA-J: Journal of Social Aspects of HIV/AIDS 4(2): 626-635.

9. Popoola BI (2013) Occupational hazards and coping strategies of sex workers in southwestern Nigeria. Health Care Women Int 34(2): 139-149.
10. Fitzgerald-Husek A, Martiniuk AL, Hinchcliff R, Aochamus CE, Lee RB (2011) I do what I have to do to survive: an investigation into the perceptions, experiences and economic considerations of women engaged in sex work in Northern Namibia. BMC Women's Health 11(35): 1472-6874.

11. Munoz J, Adedimeji A, Alawode $O$ (2010) 'They bring AIDS to us and say we give it to them': Sociostructural context of female sex workers' vulnerability to HIV infection in Ibadan, Nigeria. Sahara J 7(2): 52-61.

12. Stephenson R (2010) Community-level gender equity and extramarital sexual risk-taking among married men in eight African countries. Int Perspect Sex Reprod Health 36(4): 178-188.

13. Hunter M (2002) The Materiality of everyday sex: thinking beyond "prostitution". African Studies 61(1): 100-122.

14. Timiun GA (2017) Contextual Factors Influencing Unsafe Sexual Behaviours and the Spread of HIV/AIDS Amongst the Tiv People of North Central Nigeria.

15. Dodoo FNA, Zulu EM, Ezeh AC (2007) Urban-rural differences in the socioeconomic deprivation-Sexual behavior link in Kenya. Social Science \& Medicine 64(5): 1019-1031.

16. National Agency for the Control of AIDS (NACA) (2015). Federal Republic of Nigeria, Global AIDS response: country progress report (Nigeria GARPR), Abuja, Nigeria.

17. Timiun GA, Scrase T (2019) The Impact of Stigma and Discrimination on Adherence to Medication amongst People Living with HIV in Tiv Land, North Central Nigeria. JAMMR 30(1): 1-9. 